\title{
Influence of Plastic Deformation on Occurrence of Discontinuous Reaction in Ni-In Alloy
}

\author{
Shaban Abdou, Hassan Abd El-Hafez \\ Department of Production Engineering and Mechanical Design, Faculty of Engineering, Port Said University, Port Fouad, Egypt \\ Email: abdelhafez1@eng.psu.edu.eg
}

How to cite this paper: Abdou, S. and El-Hafez, H.A. (2018) Influence of Plastic Deformation on Occurrence of Discontinuous Reaction in Ni-In Alloy. World Journal of Engineering and Technology, 6, 492-503.

https://doi.org/10.4236/wjet.2018.62029

Received: April 18, 2018

Accepted: May 28, 2018

Published: May 31, 2018

Copyright $\odot 2018$ by authors and Scientific Research Publishing Inc. This work is licensed under the Creative Commons Attribution International License (CC BY 4.0).

http://creativecommons.org/licenses/by/4.0/

\begin{abstract}
The morphology and growth kinetics of the discontinuous precipitate in a deformed and undeformed Ni-7.5at.\%In alloy have been investigated at temperatures ranging from $667 \mathrm{~K}$ to $1030 \mathrm{~K}$ using light and scanning microscopy. Also, the dependence of the growth rate on some diffusion parameters was experimentally and theoretically studied. The investigation is observed that at all aging temperatures the alloy was observed to decompose completely by discontinuous precipitation into a fine lamellar structure of nickel-rich solid solution and $\beta\left(\mathrm{Ni}_{3} \mathrm{In}\right)$ precipitate phase. The precipitation rate depends strongly on the degree of deformation, this dependence being identical for each of the aging temperatures under investigation. Analysis of the growth rates, lamellar spacing and phase compositions for the discontinuous precipitation reaction showed that they were controlled by grain boundary diffusion. Moreover, a generally applicable procedure for calculating the driving force is presented. The driving forces, calculated in this way, should be more reliable than those calculated with the approximations based on Peterman and Hornbogen laws.
\end{abstract}

\section{Keywords}

Discontinuous Precipitation, Discontinuous Coarsening, Interlamellar Spacing, Grain Boundary Diffusion, Ni-7.5at.\%In Alloy

\section{Introduction}

The plastic deformation of metals and alloys is of high significance since it is the main component of many engineering processes. Precipitation-hardened materials are used in structural high-temperature applications because of their superior deformation properties. A typical example is the use of nickel-based super-alloys in the construction of turbine blades for aircraft engines. The micro- 
structure of these materials consists of a dispersion of $\mathrm{Ni}_{3} \mathrm{Al}(\beta)$ precipitates in a nickel-rich matrix that is often highly resistant to coarsening [3] [4].

Investigation of the effect of plastic deformation on the discontinuous precipitation reaction (DPR) is necessary to analyze the influences of rolling percentage, aging temperature, and time on the mechanical properties of the alloy [5] [6] [7].

During the aging process, supersaturated nickel alloys containing 1.4 upto 6.2at.\%In have been observed to decompose completely by discontinuous precipitation (DP) into the lamellar mixture of a face-centered cubic (FCC) nickel-rich $\alpha$ solid solution and $\beta\left(\mathrm{Ni}_{3} \mathrm{In}\right)$ precipitation [5] [6] [7].

The precipitation phenomena play an important role in metal solutions, because they modify the alloy properties, sometimes in a favourable way leading to an increase in hardness and load breaking. The final state of the precipitation process takes place over several phases [8].

Generally, the reaction of precipitation consists of the decomposition of a supersaturated solid solution $\alpha_{0}$ (mother phase) into a mixture of two phases of different compositions [3], according to the following reaction:

$$
\alpha_{0} \rightarrow \alpha+\beta
$$

where $\alpha$ is the girl phase, depleted in the alloy element and with the same structure as $\alpha_{0}$, the mother phase, and $\beta$ is the precipitated phase rich in the alloy element and can be one of the following: a mixed crystal with the same structure in the case of discontinuous precipitation in the alloy system $\mathrm{Au}-\mathrm{Ni}$ [2], a mixed crystal with a different structure in the case of the alloy system Pb-Sn [1], an intermetallic phase in the case of the alloy system Al-Zn [9], or a liquid phase in the case of the alloy system $\mathrm{Pb}-\mathrm{Bi}[5]$.

However, two types of cellular reactions were observed by Spenger and Mack [10] in this alloy system, one fine and the other coarse, in both cases the lamellas are uniformly distributed. Predel and Gust [11] have shown also the same observation, Figure 1, where the formation of the coarse lamella proceeds mainly between two fine lamellas and in both cases, the process is controlled by the diffusion on the grain boundaries. The fine lamellas are uniformly distributed; in contrast, the distribution of thick lamellas is disordered. So, there is a competition between the primary reaction of precipitation and the coalescence of the lamellas [12]. In old work, one could not observe the coarse lamellas, because probably they appear only after long annealing time. This is the same phenomenon that was observed in many alloys such as $\mathrm{Al}-\mathrm{Cu}[13], \mathrm{Au}-\mathrm{Fe}$ [11], $\mathrm{Cu}-\mathrm{Ag}$ [14] [15], Fe-Zn [16]. However, the equilibrium state is not reached in the transformation products as manifested by the presence of a solute concentration profile across the $\alpha$ lamellae. This excess of solute is diminished or even removed owing to the discontinuous coarsening (DC) reaction. Discontinuous coarsening is a reaction during which a fine-lamellar structure is transformed into a coarser one containing the same $\alpha$ and $\beta$ phases according to the reaction: 


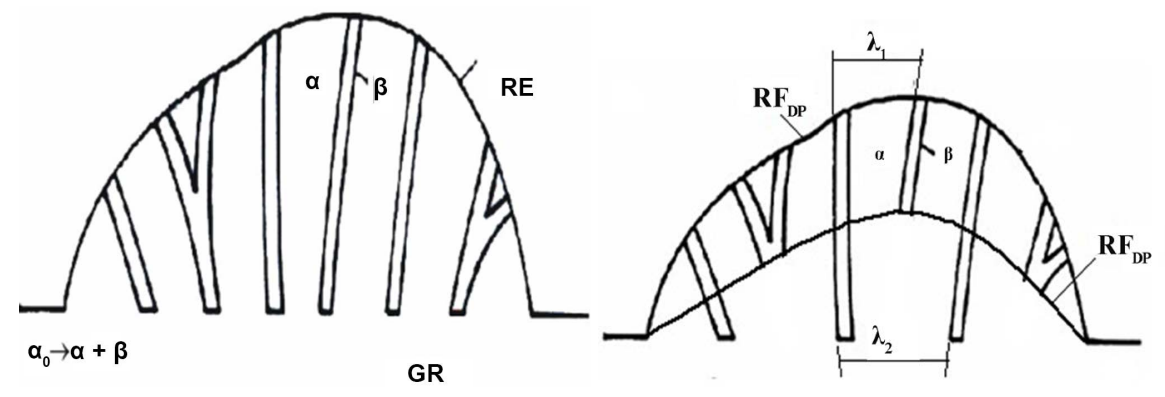

(a)

(b)

Figure 1. Schematic drawing of (a) discontinuous precipitation and (b) discontinuous coarsening [7].

$$
(\alpha+\beta) \text { fine } \rightarrow(\alpha+\beta) \text { coarse }
$$

Experimentally, it was shown that a pre-deformation with the ageing annealing affects considerably the mechanism and the kinetics of precipitation [17]. Williams [17] confirmed that under the influence of the deformation, the speed of continuous precipitation increases consequently, the degree of supersaturation in solute atom decreases, which implies a reduction in the driving force of the cellular reaction.

The growth rate, lamellar spacing and $\alpha$-phase composition of the products of the first reaction have been measured and the reaction has been shown to be controlled by grain boundary diffusion of indium at the advancing reaction front. The driving force of discontinuous precipitation reaction, which is associated with the change of free energy introduced by plastic deformation, is positively affected by the plastic deformation of a quenched solid solution.

This problem has been expressed quantitatively by Hornbogen [18] who stated that in the case when the cellular precipitation preceded recrystallization, the driving force of the transformation was equal to the sum of the driving force of precipitation and driving force resulting from the increase of lattice defects in the solution.

However, the occurrence of discontinuous precipitation in pre-deformed Ni-3at\%In alloy has been studied by Fatmi and Boumerzoug [19]. They found that this reaction is stimulated by prior cold rolling before anisothermal treatments, but below the critical deformation, which is $30 \%$ of reduction.

In the present study, the growth kinetics of the discontinuous precipitation reaction in a deformed and undeformed nickel containing 7.5at.\%In alloy have been studied for determining the rate controlling process. Also, the aim of the present work is the presentation of a modified form of the dependence the growth rates on of some diffusion parameters taken into the consideration the plastic deformation percentages.

\section{Experimental Details}

\subsection{Materials}

The ingots of Ni-In alloy were prepared by melting nickel and Indium, each of 
purity $3 \mathrm{~N} 2$. The melting was carried out in an alumina crucible in an induction furnace under argon atmosphere. The cast alloy was homogenized at $1593 \mathrm{~K}, 21$ days in evacuated quartz under a vacuum of $10^{-3} \mathrm{~Pa}$ and then water quenched. The homogenized alloy is subjected to cold plastic deformation, in a range from $5 \%$ to $30 \%$, using $\mathrm{CNC}$ rolling machine at room temperature.

\subsection{Heat Treatment}

The discontinuous precipitation and coarsening reactions were performed in a horizontal muffle furnace at a temperature ranging from $667 \mathrm{~K}$ to $1030 \mathrm{~K}$. The specimens were sealed and then aged in a quartz tube under high vacuum of $10^{-3}$ $\mathrm{Pa}$. For aging times, less than one hour the aging was performed in a lead bath. To avoid any reaction with the molten lead, the samples were wrapped in a tantalum foil.

\subsection{Metallography}

For the microscopic studies, samples were prepared by wet grinding, pre-polishing and "minimet" polishing through $7 \mu \mathrm{m}$ down to $1 \mu \mathrm{m}$ diamond paste using a Nylon polishing cloth. They were etched with a solution $10 \% \mathrm{FeCl}_{3}$ in ethanol. The etching time was 30 - $90 \mathrm{sec}$. Sometimes the samples were heated before etching in hot water to improve the etching effect.

\subsection{Hardness Test}

The hardness was measured using Standard Vickers hardness (HV) testing machine with a load of $5 \mathrm{~kg}$, loading speed of $100 \mathrm{~mm} / \mathrm{s}$ and 15 seconds holding time. The reported hardness measurements are based on an average of minimum four different locations indentations on each of the tested samples.

\section{Results and Discussion}

\subsection{Morphology}

In agreement with previous studies [5] [6] [7] the supersaturated FCC $\alpha$-phase of the solution treated and water quenched Ni-7.5at.\%In alloy decomposed completely during aging into a lamellar mixture of depleted $\alpha$ solid solution and $\beta\left(\mathrm{Ni}_{3} \mathrm{In}\right.$ of $\mathrm{DO}_{19}$ structure ) precipitate, Figure 2. Generally, the discontinuous precipitation reaction (DPR) occurs by migrating grain boundaries between two supersaturated grains boundary from one grain into the other leaving behind the lamellar mixture. Abdou et al. [7] show that the discontinuous cells consist of the same two phases (depleted $\alpha$ and $\beta$ precipitate) as the discontinuous precipitation cells into which they are growing. Figure 2 (c) showing that the discontinuous coarsening reaction occurred after deformation around the grain boundary, not on subgrain.

\subsection{Microhardness Analysis}

Figure 3 shows the relationship between the Vickers microhardness of Ni-7.5at.\%In alloy versus the deformation percentage before and after 


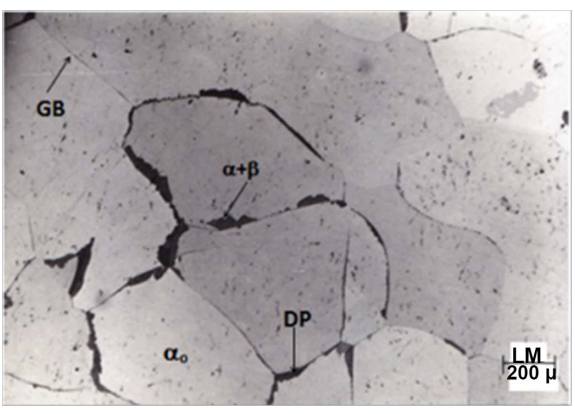

(a)

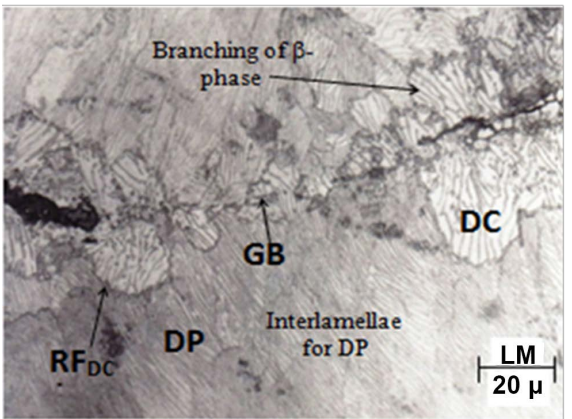

(c)

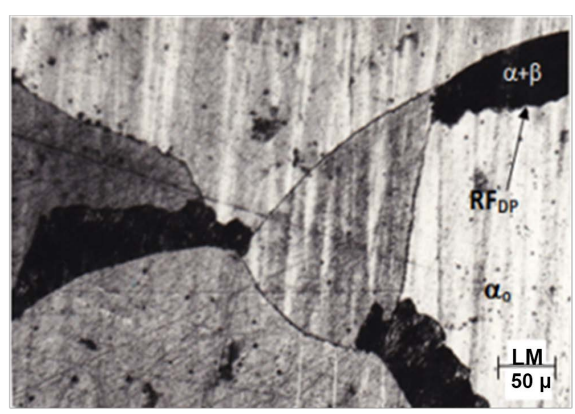

(b)

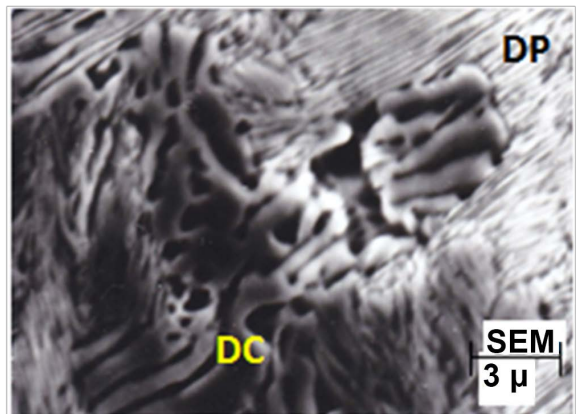

(d)

Figure 2. Light and SEM micrographs of discontinuous precipitation and growing the discontinuous precipitation and coarsening for undeformed and deformed $\mathrm{Ni} 7.5 \% \mathrm{In}$ alloy. Undeformed (a) (b) and Deformed (c) (d). (a) Undeformed aging at $450^{\circ} \mathrm{C} / 1 \mathrm{~h}$; (b) Undeformed aging at $602^{\circ} \mathrm{C} / 3 \mathrm{~h}$; (c) Deformed alloy aging at $450^{\circ} \mathrm{C} / 195 \mathrm{~h}$; (d) Deformed alloy at aging $510^{\circ} \mathrm{C} / 210 \mathrm{~h}$.

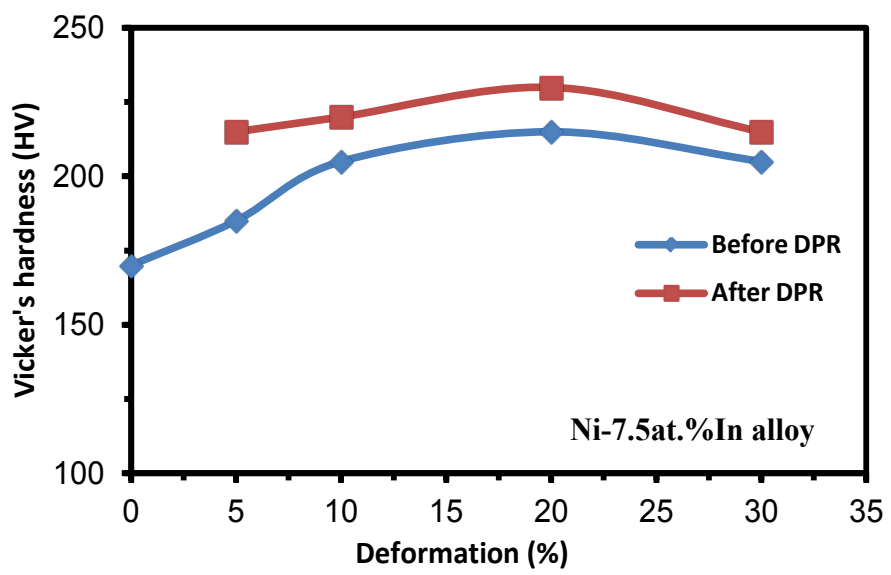

Figure 3. The relationship between the Vickers hardness versus the plastic deformation in Ni-7.5 at.\%In alloy (before and after reaction).

discontinuous precipitation reaction for deformed and undeformed alloy. The curve reflects the effect of hardening by plastic deformation [9].

\subsection{Cell Growth Rates}

The reaction front migration rates for discontinuous precipitation (DP) were determined from the slopes of the plots of the true cell width as a function of the 
aging time. The true cell width $w$ was taken to be $\pi / 4$ times the arithmetic average of the apparent cell width $w^{\prime}$ measured statistically on a photomicrograph [7]. The values $w^{\prime}$ were obtained by measuring the distance from the start of a cell to its leading edge. About 35 measurements were performed for each aging condition. The migration rates for discontinuous precipitation in deformed and undeformed Ni-7.5.at\%In alloy are shown in Figure 4. The values of the growth rate due to the plastic deformation for the discontinuous precipitation and coarsening reactions are presented in Table 1 and Table 2 . The interlamellar spacing, $\lambda_{1}, \lambda_{2}$ of precipitates in cells of DP was obtained by measuring 15 - 32 regions of the apparent lamellar spacing $\lambda^{\prime}$. The following equation holds true $\lambda^{\prime}=\pi \lambda / 4 \quad$ [7].

Figure 5 demonstrates clearly states that the plastic deformation has no effect on the interlamellar spacing for the discontinuous precipitation.

The activation energy $(Q)$, for the discontinuous precipitation reaction in undeformed alloys, can be calculated from the following equation.

$$
v=v_{o} \mathrm{e}^{-Q / R T}
$$

where $R$ is the universal gas constant and $T$ absolute aging temperature. $Q$ may be calculated from the logarithm of the growth factor resulting from deformation. It has been found that the definitely affects the values of the pre-exponential factor $v_{o}$ Christian [20] forwarded the following equation;

$$
v=\delta \frac{\Delta G}{R T} \mathrm{e}^{-Q / R T}
$$

where $\delta$ is the thickness of the reaction front and $\underline{\Delta G}$ is the net free energy change for the transformation one mole of the supersaturated solid solution by the DP to depleted solid solution and precipitate phase. The value of the driving

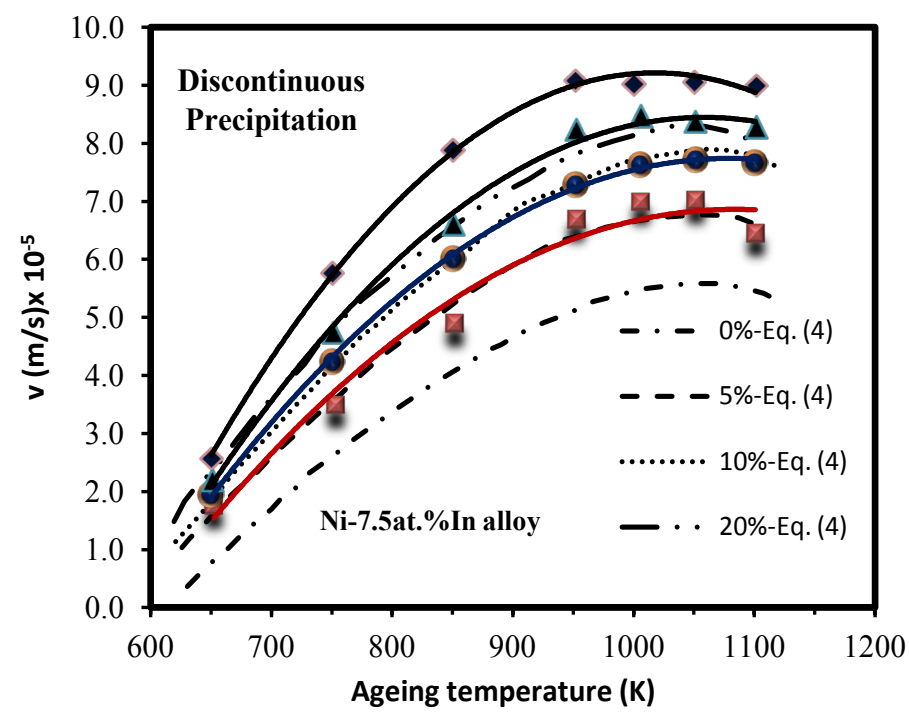

Figure 4. The growth rate for discontinuous precipitation in $\mathrm{Ni-7.5at, \% In} \mathrm{alloy} \mathrm{versus} \mathrm{the} \mathrm{aging} \mathrm{temperature} \mathrm{at} \mathrm{different} \mathrm{rolling} \mathrm{per-}$ centage. 


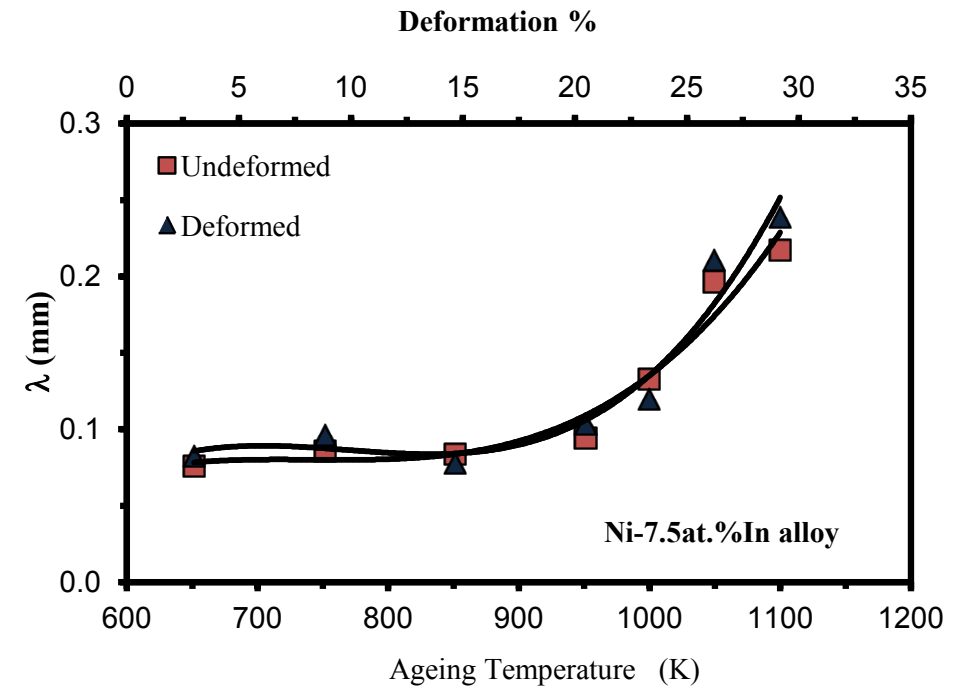

Figure 5. The interlamellar spacing for discontinuous precipitation (DP) versus the aging temperature in deformed and undeformed $\mathrm{Ni}-7.5 \mathrm{at} \% \mathrm{In}$ alloy.

Table 1. The growth rate and interlamellae spacing values for the discontinuous precipitation due to the plastic deformation in a $\mathrm{Ni}-7.5 \mathrm{at} \%$ In alloy at different aging temperature.

\begin{tabular}{|c|c|c|c|c|c|c|c|}
\hline \multirow{2}{*}{$\mathrm{T}(\mathrm{K})$} & \multirow{2}{*}{$\begin{array}{c}\mathrm{Xe} \\
\text { at. (\%) }\end{array}$} & \multirow{2}{*}{$\begin{array}{c}\mathrm{X} 1 \\
\text { at. (\%) }\end{array}$} & \multicolumn{4}{|c|}{$\mathrm{V} 1(\mathrm{~m} / \mathrm{s})$} & \multirow{2}{*}{$\begin{array}{c}\lambda_{1} \\
(\mu \mathrm{m})\end{array}$} \\
\hline & & & $0 \%$ & $5 \%$ & $10 \%$ & $20 \%$ & \\
\hline 650 & 0.38 & 1.38 & $2.51 \times 10^{-11}$ & $3.55 \times 10^{-11}$ & $5.62 \times 10^{-11}$ & $1.00 \times 10^{-10}$ & 0.070 \\
\hline 750 & 0.46 & 1.45 & $5.02 \times 10^{-10}$ & $1.78 \times 10^{-9}$ & $5.62 \times 10^{-9}$ & $3.16 \times 10^{-8}$ & 0.080 \\
\hline 850 & 1.31 & 1.72 & $6.31 \times 10^{-9}$ & $5.01 \times 10^{-8}$ & $1.7 \times 10^{-7}$ & $1.80 \times 10^{-6}$ & 0.085 \\
\hline 950 & 1.50 & 2.48 & $1.78 \times 10^{-7}$ & $5.60 \times 10^{-7}$ & $3.98 \times 10^{-6}$ & $1.78 \times 10^{-5}$ & 0.090 \\
\hline 1000 & 2.68 & 3.17 & $3.16 \times 10^{-7}$ & $1.00 \times 10^{-6}$ & $5.62 \times 10^{-6}$ & $1.73 \times 10^{-5}$ & 0.130 \\
\hline 1050 & 4.32 & 4.28 & $3.55 \times 10^{-7}$ & $1.26 \times 10^{-6}$ & $5.01 \times 10^{-6}$ & $1.70 \times 10^{-5}$ & 0.190 \\
\hline 1100 & 5.96 & 6.30 & $1.26 \times 10^{-7}$ & $1.10 \times 10^{-6}$ & $4.32 \times 10^{-6}$ & $1.60 \times 10^{-5}$ & 0.210 \\
\hline
\end{tabular}

Table 2. The growth rate and interlamellae spacing values for the discontinuous coarsening due to the plastic deformation in a Ni-7.5at\%In alloy at different aging temperature.

\begin{tabular}{|c|c|c|c|c|c|c|c|}
\hline \multirow{2}{*}{$\mathrm{T}(\mathrm{K})$} & \multirow{2}{*}{$\begin{array}{c}\mathrm{Xe} \\
(\mathrm{at} \%)\end{array}$} & \multirow{2}{*}{$\begin{array}{c}\mathrm{X} 2 \\
\text { (at\%) }\end{array}$} & \multicolumn{4}{|c|}{$\mathrm{V} 2(\mathrm{~m} / \mathrm{s})$} & \multirow{2}{*}{$\lambda_{2}$} \\
\hline & & & $0 \%$ & $5 \%$ & $10 \%$ & $20 \%$ & \\
\hline 650 & 0.38 & 0.33 & $6.31 \times 10^{-13}$ & $1.00 \times 10^{-12}$ & $1.26 \times 10^{-12}$ & $5.65 \times 10^{-12}$ & 0.42 \\
\hline 750 & 0.46 & 0.34 & $4.47 \times 10^{-12}$ & $2.50 \times 10^{-11}$ & $5.62 \times 10^{-11}$ & $1.20 \times 10^{-10}$ & 0.45 \\
\hline 850 & 1.31 & 0.90 & $2.24 \times 10^{-11}$ & $3.16 \times 10^{-10}$ & $6.31 \times 10^{-10}$ & $3.16 \times 10^{-9}$ & 0.46 \\
\hline 950 & 1.50 & 1.65 & $5.01 \times 10^{-10}$ & $1.00 \times 10^{-9}$ & $4.47 \times 10^{-9}$ & $5.62 \times 10^{-9}$ & 0.51 \\
\hline 1000 & 2.68 & 2.65 & $5.62 \times 10^{-10}$ & $1.78 \times 10^{-9}$ & $1.58 \times 10^{-9}$ & $3.16 \times 10^{-8}$ & 0.68 \\
\hline 1050 & 4.32 & 2.90 & $4.47 \times 10^{-10}$ & $1.75 \times 10^{-9}$ & $5.62 \times 10^{-8}$ & $3.55 \times 10^{-8}$ & 0.95 \\
\hline 1100 & 5.96 & 3.20 & $1.41 \times 10^{-10}$ & $1.71 \times 10^{-9}$ & $5.60 \times 10^{-9}$ & $3.50 \times 10^{-8}$ & 1.16 \\
\hline
\end{tabular}


force, $\underline{\Delta G}$ of transformation in an undeformed alloy was determined from the relationship given by Cahn [21];

$$
\Delta G=P \Delta G_{c}+\frac{2 \sigma_{\alpha / \beta V_{m}}}{\lambda}
$$

where; $\Delta G_{c}$ is the chemical free energy for the reaction, $P$ is the fraction of the total chemical free energy, $\sigma_{\alpha / \beta}$ of the free energy per unit area of the $\alpha / \beta$ interface, $V_{m}$ the molar volume for the $\alpha+\beta$ mixtures and $\lambda$ is the interlamellar spacing.

The increase of the plastic strain by rolling increases the driving forces for occurrences the discontinuous precipitation and discontinuous coarsening reactions. Otherwise, the factor $\delta$ remains constant with the increase the degree of deformation and small changes of the width of the grain boundary can be achieved [22].

The relationship between the growth rate and the degree of plastic strain for Ni-7.5\%In alloy is shown in Figure 4. The method of the determination the value $\Delta G_{c}$ was verified employing Hornbogen's statement noting that the value of the driving force of recrystallization $\Delta F_{R}$ cannot exceed the value of $\Delta G$. Otherwise, recrystallization would precede the process of DP. Thus, by applying the above rule, it is found that regularity is retained below the $20 \%$ of strain and for small changes of the factor $\lambda_{\Psi}$. Where $\delta_{\Psi}$ is a factor dependent upon the shape and behavior of the interlamellae growth and equal $\lambda_{G B} / \lambda_{R E} \quad\left(\lambda_{G B}\right.$ is the interlamellae spacing at the grain boundary and $\lambda_{R E}$ is the interlamellae at the reaction front). To introduce a correction resulting from the changes of $\lambda_{\Psi}$, a modified relation was applied that relation express the effect of plastic deformation on the changes of the driving force of cell transformation this correction describes the increase in the pre-exponential factor resulting from deformation. It is a product of the acceleration parameter $P_{Z}$ of the transformation and of the change of the deformation degree [23]. The parameter $P_{Z}$ expressed by the relation;

$$
P_{Z}=\frac{1}{1 /\left(z_{1}-z_{o}\right)}\left(\ln v_{1} / \ln v_{o}\right)
$$

The modified relation expressing the dependence of the transformation rate upon the aging temperatures is as follows;

$$
v=\delta_{\Psi} \mathrm{e}^{\left(\mathrm{P}_{\mathrm{Z}} \Delta \mathrm{Z}\right)} \frac{\Delta G}{R T} \mathrm{e}^{-Q / R T}
$$

The values of $V$, as determined from Equation (4), are smaller than those determined experimentally as shown in Figure 4. Such discrepancy is due to the assumption that the driving force of recrystallization equals the driving force for the discontinuous precipitation reaction at the whole of plastic strain.

\subsection{Analysis of First Cell Growth Kinetics}

The growth rate, lamellar spacing and phase composition data for first cell growth are presented in Table 1, Table 2, Figure 4 and Figure 5 have been 
Table 3. The grain boundary diffusion $\left(s \delta D_{b}\right)$ for discontinuous precipitation reaction in deformed and undeformed $\mathrm{Ni}-7.5$ at.\%In alloy at different rolling percentage.

\begin{tabular}{|c|c|c|c|c|c|c|c|c|c|c|c|c|}
\hline \multicolumn{13}{|c|}{$\log s \delta D_{b}\left(\mathrm{~m}^{3} / \mathrm{s}\right)$} \\
\hline \multirow{3}{*}{$\begin{array}{c}\text { Reaction } \\
\text { Model } \\
\mathrm{T}(\mathrm{K})\end{array}$} & \multicolumn{12}{|c|}{ Discontinuous Precipitation } \\
\hline & \multicolumn{4}{|c|}{ Turnbull Analysis } & \multicolumn{4}{|c|}{ Aaronson \& Liu Analysis } & \multicolumn{4}{|c|}{$\begin{array}{c}\text { Petermann \& Hornbogen } \\
\text { Analysis }\end{array}$} \\
\hline & $0 \%$ & $5 \%$ & $10 \%$ & $20 \%$ & $0 \%$ & $5 \%$ & $10 \%$ & $20 \%$ & $0 \%$ & $5 \%$ & $10 \%$ & $20 \%$ \\
\hline 650 & 28 & 25.7 & 24.8 & 23.5 & 26.5 & 25 & 24 & 22.4 & 26 & 25 & 21.6 & 19.5 \\
\hline 750 & 25.1 & 23.8 & 23 & 21.7 & 24.8 & 23.4 & 22 & 21.3 & 23.7 & 21.5 & 19.9 & 19 \\
\hline 850 & 23.1 & 22.5 & 21.7 & 21 & 23 & 21.8 & 21 & 20.2 & 21.7 & 19.7 & 18.9 & 17.6 \\
\hline 950 & 21.5 & 21.2 & 20.7 & 20.3 & 21.4 & 20.5 & 19.6 & 19 & 20 & 19.3 & 18 & 17.3 \\
\hline 1050 & 21.1 & 20.6 & 20 & 19.8 & 20.8 & 20 & 19.5 & 18.7 & 19.4 & 17.8 & 17.5 & 17.1 \\
\hline 1100 & 20.5 & 20.1 & 19.8 & 19.2 & 19.5 & 19 & 18.1 & 17.8 & 18.1 & 17.5 & 17 & 16.1 \\
\hline
\end{tabular}

Table 4. Arrhenius parameters ( $Q o$ and $\left(s \delta D_{b}\right) o$ ) from different diffusion theories at different rolling percentage for the occurring the discontinuous precipitation and coarsening reactions in deformed and undeformed $\mathrm{Ni}-7.5 \mathrm{at} . \%$ In alloy.

\begin{tabular}{|c|c|c|c|c|c|c|c|c|}
\hline \multicolumn{9}{|c|}{$\log s \delta D_{b}\left(\mathrm{~m}^{3} / \mathrm{s}\right)$} \\
\hline \multirow{3}{*}{$\begin{array}{c}\text { Reaction } \\
\text { Model } \\
\mathrm{T}(\mathrm{K})\end{array}$} & \multicolumn{8}{|c|}{ Discontinuous Precipitation } \\
\hline & \multicolumn{4}{|c|}{ Turnbull Analysis } & \multicolumn{4}{|c|}{ Aaronson \& Liu Analysis } \\
\hline & $0 \%$ & $5 \%$ & $10 \%$ & $20 \%$ & $0 \%$ & $5 \%$ & $10 \%$ & $20 \%$ \\
\hline 650 & 28 & 25.7 & 24.8 & 23.5 & 26.5 & 25 & 24 & 22.4 \\
\hline 750 & 25.1 & 23.8 & 23 & 21.7 & 24.8 & 23.4 & 22 & 21.3 \\
\hline 850 & 23.1 & 22.5 & 21.7 & 21 & 23 & 21.8 & 21 & 20.2 \\
\hline 950 & 21.5 & 21.2 & 20.7 & 20.3 & 21.4 & 20.5 & 19.6 & 19 \\
\hline 1050 & 21.1 & 20.6 & 20 & 19.8 & 20.8 & 20 & 19.5 & 18.7 \\
\hline 1100 & 20.5 & 20.1 & 19.8 & 19.2 & 19.5 & 19 & 18.1 & 17.8 \\
\hline
\end{tabular}

analyzed according to the theories of Tu and Turnbull [1] and Aaronson and Liu [2]. The theories assume that cell growth is controlled by boundary diffusion $D_{b}$, in the advancing cell interface. Therefore, analysis of the data involves substituting the measured quantities into the theoretical growth rate equations, calculating the unknown values of $\left(s \delta D_{b}\right)$ and comparing them with the values determined by Gust et al. [24] for Indium tracer diffusion in stationary grain boundaries. All calculations have been assured that the composition of the $\alpha$-phase is as given in Table 1 and Table 2, show the $\beta$-phase and $\alpha$-equilibrium values given by Chuang et al. [25] [26] considering the effect of continuous precipitation can be neglected.

\subsection{Turnbull Analysis}

According to Turnbull and Tu [1], who modified Zener's volume diffusion control theory for eutectoid decomposition to boundary diffusion controlled growth for discontinuous precipitation; the growth rate of first cells is given by: 


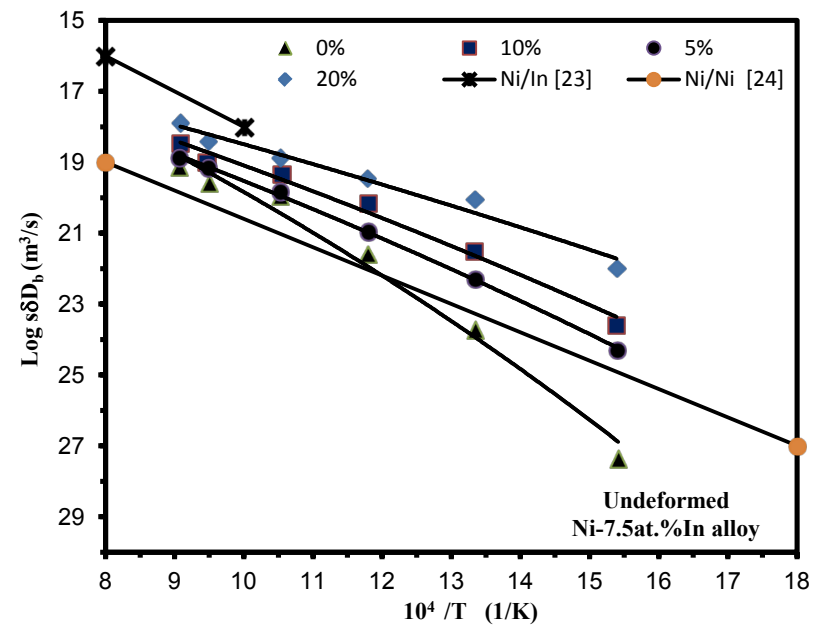

(a)

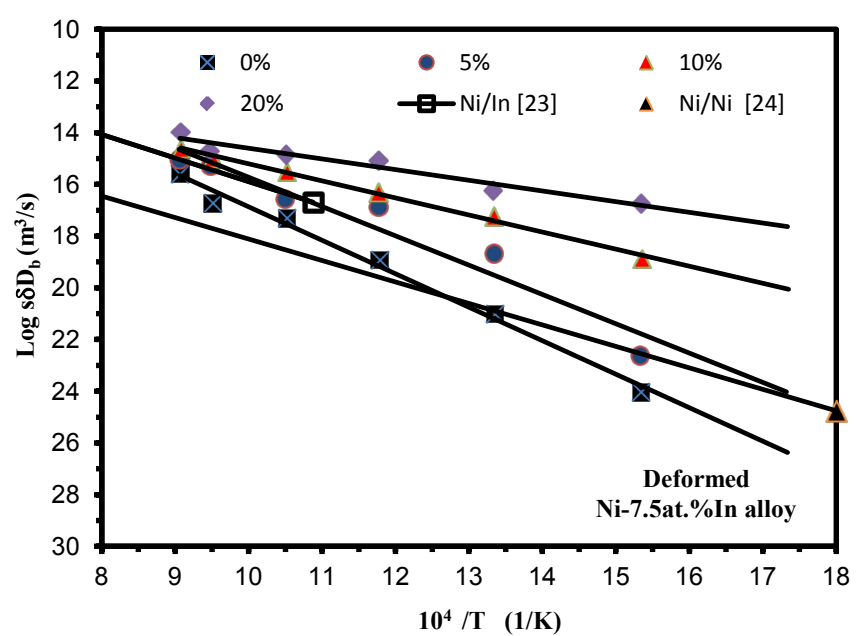

(b)

Figure 6. Grain boundary diffusion $\left(s \delta D_{b}\right)\left(s \delta D_{b}\right) o$ migrating grain boundaries for discontinuous precipitation reaction in undeformed (a) and deformed (b) Ni-7.5at.\%In alloy, according Turnbull and Aaronson and Liu models [1] [2]. (a) Undeformed; (b) Deformed.

$$
v=\frac{x_{o}^{\alpha}-x_{1}^{\alpha}}{x_{o}^{\alpha}}\left(\frac{s \delta D_{b}}{\lambda_{1}^{2}}\right)
$$

where $s$ is the segregation factor, $\delta$ is the interlamellar spacing and $D_{b}$ is the grain boundary diffusion. In Equation (5) $x_{1}^{\alpha}$, the concentration of In the $\alpha$ lamellae of the first cells, was used rather than the equilibrium solvus composition $x_{o}^{\alpha}$. The values $\left(s \delta D_{b}\right.$ ) obtained by substituting the values of $v_{1}, \lambda_{1}$ and concentration values into this equation are presented in Table 3 and Figure 6(a). The diffusion parameters $\left(s \delta D_{b}\right) o$ and $Q o$ obtained from them are given in Table 4.

\section{Conclusions}

- Supersaturated solid solution of Ni-7.5 at.\%In alloy deformed and undeformed is decomposed completely by discontinuous precipitation and coarsening into a lamellar mixture of depleted $\alpha$ and $\beta$ phases during aging at temperatures ranging from 667 to $1030 \mathrm{~K}$.

- The precipitation rate depends strongly on the degree of deformation, this dependence being identical for each of the aging temperature under the solvus line.

- The plastic deformation is highly affected the mechanism of occurring discontinuous reactions.

- Analysis of the growth kinetics using Aaronson and Liu, Turnbull gives similar results, which suggest that both reactions are controlled by grain boundary diffusion in the reaction front.

- The driving force of discontinuous transformation in a deformed alloy is increased continuously as a result of plastic deformation which introduces micro-twins. 


\section{Acknowledgements}

The authors would like to thank Prof. Dr. W. Gust, Max-Plank-Institute, Stuttgart-Germany for providing the alloy used in this study.

\section{References}

[1] Tu, K. and Turnbull, D. (1971) Morphology and Kinetics of Cellular Dissolution of the Pb-Sn Alloy. Metallurgical Transactions, 2, 2509-2515. https://doi.org/10.1007/BF02814889

[2] Aaronson, H.I. and Liu, Y.C. (1968) On the Turnbull and the Cahn Theories of the Cellular Reaction. Scripta Metallurgica, 2, 1-7. https://doi.org/10.1016/0036-9748(68)90157-9

[3] Hort, W. and Johnson, W.C. (1994) Diffusional Boundary Conditions during Coarsening of Elastically Interacting Precipitates. Metallurgical and Materials Transactions A, 25, 2695-2703. https://doi.org/10.1007/BF02649222

[4] Araki, H., et al. (1994) Anomalous Diffusion of Aluminum in $\beta$-Titanium. Metallurgical and Materials Transactions A, 25, 874-876. https://doi.org/10.1007/BF02665465

[5] Budurov, S. and Boshinov, W. (1980) Cellular Precipitation Kinetics in Supersaturated FCC Nickel-Indium Alloy. Zeitschrift fur Metallkunde, 71, 617-620.

[6] Chuang, T., Gust, W. and Fournelle, R. (1986) Review of Discontinuous Precipitation and Dissolution. Anais 7cbecimat, UFSC, Florianopolis, 37-41.

[7] Abdou, S., et al. (1987) Three Discontinuous Reactions in Ni-In Alloys: Precipitation, Coarsening and Dissolution. Phase Transformations, 87, 258-261.

[8] Kassner, M.E., Smith, K. and Eliasson, V. (2015) Creep in Amorphous Metals. Journal of Materials Research and Technology, 4, 100-107. https://doi.org/10.1016/j.jmrt.2014.11.003

[9] Hamoudi, M., et al. (2012) Discontinuous Precipitation and Dissolution under the Influence of the Plastic Strain and Temperature in Al-15 at.\% $\mathrm{Zn}$ and $\mathrm{Al}-30$ at.\% $\mathrm{Zn}$ Alloys. Materials Sciences and Applications, 3, 433-441. https://doi.org/10.4236/msa.2012.37061

[10] Spenger, C.W. and Mack, D.J. (1981) Initiation and Growth of the Grain Boundary Discontinuous. Materials Transactions JIM, 5, 53-54.

[11] Predel, B. and Gust, W. (1974) Beitrag zur kinetik der diskontinuierlichen Ausscheidung in Kupfer-Indium-Mischkristallen mit 7,5 At.-\% Indium. Materials Science and Engineering, 16, 239-249. https://doi.org/10.1016/0025-5416(74)90161-X

[12] Bensaada, S., Mazouz, H. and Bouziane, M.T. (2011) Discontinuous Precipitation and Dissolution in Cu-4.6 at\% In Alloy under Effect of Plastic Deformation and the Temperature. Materials Sciences and Applications, 2, 1471-1479.

[13] Barrand, P., et al. (1967) Discontinuous Precipitation in Deformed Al-Cu Alloys. Acta Metallurgica, 15, 1553-1557. https://doi.org/10.1016/0001-6160(67)90188-5

[14] Borchers, H., Scharfenberg, W. and Zurstege, R. (1968) Precipitation Behavior of $\alpha$-Solid Solutions of the Fe-Sn System. Acta Metallurgica, 8, 405-408.

[15] Leo, W. (1967) Microstructure and Internal Stresses in Cyclically Deformed Al and Cu Single Crystals. Zeitschriftfür Metallkunde, 7, 456-458.

[16] Predel, B. and Frebel, M. (1972) Die gegenseitige beeinflussung verschiedener 
Ausscheidungsreaktionen in $\alpha$-Fe-Zn-Mischkristallen. Acta Metallurgica, 20, 1259-1268. https://doi.org/10.1016/0001-6160(72)90056-9

[17] Williams, D. and Butler, E. (1981) Grain Boundary Discontinuous Precipitation Reactions. International Metals Reviews, 26, 153-183.

https://doi.org/10.1179/imtr.1981.26.1.153

[18] Hornbogen, E. (1972) Systematics of the Cellular Precipitation Reactions. Metallurgical Transactions, 3, 2717-2727. https://doi.org/10.1007/BF02652839

[19] Fatmi, M. and Boumerzoug, Z. (2010) Influence of Plastic Deformation on Occurrence of Discontinuous Precipitation Reaction in Ni-3at\% In Alloy. Physica B: Condensed Matter, 405, 4111-4115. https://doi.org/10.1016/j.physb.2010.06.062

[20] Christian, J.W. (2002) The Theory of Transformations in Metals and Alloys.

[21] Cahn, J.W. (1959) The Kinetics of Cellular Segregation Reactions. Acta Metallurgica, 7, 18-28. https://doi.org/10.1016/0001-6160(59)90164-6

[22] Predel, B. and Gust, W. (1975) Die Kinetik der feinlamellaren diskontinuierlichen Ausscheidung in übersättigten Mischkristallen des Systems CuIn. Materials Science and Engineering, 17, 41-50. https://doi.org/10.1016/0025-5416(75)90028-2

[23] Pawlowski, A. (1977) Discontinuous Decomposition in Aluminum-Zinc and Aluminum-Silver Alloys. Arch Hunt, 22, 621-650.

[24] Gust, W., et al. (1982) Measurement of the Grain Boundary Diffusion of In in Ni Bicrystals by the SIMS Technique. Acta Metallurgica, 30, 75-82. https://doi.org/10.1016/0001-6160(82)90046-3

[25] Chuang, T.-H., et al. (1986) Mechanisms of Grain Boundary Migration during Discontinuous Dissolution in Ni-In Polycrystals. Japan Inst. of Metals, Sendai.

[26] Chuang, T.H., et al. (1988) Discontinuous Coarsening of Discontinuous Precipitate in a Ni-7.5 at \% In Alloy. Acta Metallurgica, 36, 775-785.

https://doi.org/10.1016/0001-6160(88)90111-3 